\title{
STRATEGIC RESPONSE CAPABILITY AND FIRM COMPETITIVENESS: HOW OMOLUABI LEADERSHIP MAKES A DIFFERENCE
}

\author{
Abiodun Babatunde ONAMUSI \\ Department of Management \& Accounting, Lead City University, Ibadan, Oyo State, Nigeria \\ abiodunonamusi@gmail.com
}

\begin{abstract}
This study assessed the effect of strategic response capability on firm competitiveness of selected paint manufacturers in Lagos State, Nigeria, more so, it ascertained the moderating effect of Omoluabi leadership on the interaction between strategic response capability and firm competitiveness. The study adopted a cross-sectional survey design and a sample of 343 employees of eighteen selected paint manufacturers in Lagos State, Nigeria. A hierarchical regression analysis to test three-way interaction hypotheses was conducted. The results showed that strategic response capability had a positive and significant effect on firm competitiveness $\left(R^{2}=0.46 .3, F(1,341) 294.165, p=\right.$ $.000)$. Further analysis showed that the interaction term of strategic response capability and Omoluabileadership explained the increase in firms' competitiveness $\left(\Delta R^{2}=0.039, p=0.000\right)$ with the introduction of Omoluabi leadership as a moderator. The study through its findings established that strategic response capability enhances firm competitiveness through the deployment of Omoluabi leadership. Hence, this study recommends that firms should strengthen their strategic response capability and encourages leadership to imbibe the philosophy of Omoluabi leadership this is because such a leadership attribute potentially improves firm competitiveness.
\end{abstract}

Keywords: Dynamic Capability theory, firm competitiveness, Omoluabi leadership, Strategic response capability, contingency theory

\section{INTRODUCTION}

The paint manufacturing industry going by the Manufacturers Association of Nigeria (MAN) report in 2019 suggested that despite the prospect of the industry arising from increasing investment in luxury homes, hotels, and rising housing estate across States in the country, however, the paint manufacturers in Nigeria are experiencing some unique challenges that have affected the overall corporate performance of the registered players in the industry. First, it is the issue of unregistered paint makers who offer adulterated products; they offer inferior quality and have the capability to quickly respond to customer orders, more so at a lower cost compared to the known-registered brands. Also, there is scarcity and high cost of sourcing raw materials given the limited availability of local substitutes. Many middle-income earners build 
houses without painting them, and the harsh operating environment in Nigeria is represented by poor infrastructure: epileptic power supply, bad road networks, and credit accessibility challenges coupled with high insecurity within its borders. The coronavirus pandemic has shifted most individuals, companies, and the government from building houses to concentrating on surviving the pandemic. The ripple effect of these issues identified has partly led to a negative consequence for Nigeria's registered paint manufacturer. Amongst the consequences as established by MAN (2018) include loss of sales revenue, increase customer complaints, and overall weak firm competitiveness.

Given the challenges faced by these manufacturers, scholars suggested that developing an effective strategic response is key to addressing some of these challenges, especially on the issues of unregistered paint maker and in responding to dynamic macro-economic uncertainties in the wake of the covid-19 pandemic (Arokodare, 2020; Kabue et al., 2019). Many empirical studies have been written to validate strategic response capability's performance-effect in several research contexts (Arokodare 2020; Gerald et al., 2020; Lin et al., 2018). However, this subject matter has received less attention from scholars in Nigeria, that focus on paint manufacturers in Lagos State, Nigeria. Hence, suggesting a gap worthy of investigation. Furthermore, given the relevance of leadership in drafting, implementing, and influencing organizational strategies, culture, and the internal organization climate; this study argues that while strategic response capability may assist in positioning paint manufacturers for better performance, the whole architecture of strategic response capability still needs leadership that will consistently drive its implementation and creates a framework that allows its human resource to achieve the desired result. If the organization intends to continue to progress profitably, it needs leadership that will consistently allow that to happen.

Studies on leadership have positioned how different leadership philosophy: transformational (Deichmann \& Stam, 2015; Prasad \& Junni, 2016), transactional (Afsar et al., 2017; Obeidat \& Tarhini, 2016), and authentic leadership (Gill et al., 2018; Ibarra, 2015) have influenced change management, operational efficiency and organizational performance in different research context. However, the majority of these leadership approaches were conceptualized from the perspective of scholars from developed economies. Although there is nothing wrong with using these approaches in the developing economy context, however, there is cultural uniqueness in the developing economies; for example, in Nigeria, these leadership theories do not explicitly address that despite their universal applicability and acceptance. Consequently, the study proposed a home-grown leadership perspective called Omoluabi leadership. Although studies exist in the literature on the Omoluabi perspective to explain ethical issues in Yoruba cultural orientation and as it relates to the societal norm, values, education, and political system in Nigeria (Adebowale \& Onayemi, 2019; Akanbi \& Jekayinfa, 2016; Akinboye, 2015; Oke, 2016; Olanipekun, 2017). Nevertheless, to the best of the researcher's knowledge, empirical studies in the field of strategic 
management that has substantiated the effect of the Omoluabi leadership trait either as a first-order or as a second-order condition that enhance organizational performance is rare, and this presents another gap in literature worthy of study. To this end, the study proposed that strategic response capability would significantly affect the firm competitiveness of paint manufacturers in Lagos State, Nigeria. Also, Omoluabi leadership's adoption would enhance the interaction between strategic response capability and firm competitiveness of paint manufacturers in Lagos State, Nigeria.

\section{LITERATURE REVIEW}

\subsection{Theoretical Framework and Hypotheses Development}

Empirical studies in management have been underpinned on several theories to provide theoretical justification for their studies. This study follows a similar procedure to draw on three theoretical perspectives (Dynamic capability theory, Contingency theory, and Omoluabi perspective) to substantiate the moderating effect of Omoluabi leadership on strategic response's performance effect capability. First, the DCT perspective suggest that firms who possess the capability to integrate, develop internal and external response capabilities peculiar to it and continuously reconfigure these capabilities to accommodate market dynamics and changing macro-environment would achieve superior performance (Laaksonen \& Peltoniemi, 2016; Wang et al., 2015). This suggests that there must be a direct and indirect interaction between the ownership of dynamic internal (response)-external (response) capabilities and firm competitiveness (Bartocci, 2019; Breznik \& Lahovnik, 2016; Ogunkoya et al., 2014). The strategic response capability, such as internal and external response capabilities considered in this study, are dynamic capability elements that explain how firms can achieve superior performance.

Second, the contingency perspective emphasized that beyond the organization, other factors can influence performance. This narrative is sustained in the interactive perspective of fit as a moderator. Specifically, if an organization can fit itself with contingent factors such as leadership, culture, strategy, technology, structure, and environment, such alignment guarantees improved performance (Nwonu et al., 2017; Ngo et al., 2019; Nwonu et al., 2017; Oliveira et al., 2018; Titus \& Anderson 2018). To buttress this discussion, according to the contingency theory, where the interaction between two variables (strategic response capability and firm competitiveness) is influenced as a result of the introduction of a third variable (Omoluabi leadership), then the contingency theory of fit-as-moderator holds. Conceived from a Yoruba worldview (Yoruba is an ethnic group in Nigeria), Omoluabi describes the personality attribute of a person/leader that encapsulate the culture of hard work, transparency, accountability, respect for employees, possession of sound character, and wisdom in judgment; one equipped to handle problems both within and outside of the organization. More so, such individuals consistently use a socially approved 
expression in addressing employees, possess excellent knowledge of the business, and communicate effectively with the capacity to keep everyone's interest within the organization (Adebowale \& Onayemi, 2019; Olanipekun, 2017). The 'Yoruba' perspective considers the individual who possesses these attributes to have a unique capability, one that the society values. More so, Olanipekun (2017) revealed that such a person would influence positive outcomes within the community. Hence, a leader who exhibits these Omoluabi personality traits is highly likely to significantly improve the firm's operational efficiency, motivate the employees, and consequently enhance firm performance.

The narrative of Omoluabi's perspective and the contingency theory provided the theoretical explanation for leadership's relevance as a contingent factor, explaining how, from a Yoruba view, such contingent enhances the interaction between strategic response capability and firm competitiveness. Overall, the $\mathrm{DCT}, \mathrm{CT}$, and Omoluabi perspective's central supposition provided the theoretical explanations for the variables under investigation and the hypotheses formulated. Given the preceding, this study proposed that: (H1) Firm who possess strategic response capability will achieve significant variation in firm competitiveness. More so, $(\mathrm{H} 2)$ the interaction term of strategic response capability and Omoluabi leadership would moderate the effect strategic response capability has on firm competitiveness.

\subsection{EMPIRICAL REVIEW}

\subsubsection{Strategic Response Capability and Firm Competitiveness}

Strategic management scholars emphasize the need for firms to possess strategic response capability as a precondition for achieving firm competitiveness in a changing environment characterized by erratic consumer behavior, intense global/local competitive rivalry, inconsistent government policies, disruptive innovations, and weak purchasing power (Arokodare et al., 2019; Onamusi, 2020). The narrative in Arokodare et al. (2020) suggested that much can be achieved for firms through the ownership and deployment of strategic response capability.

Yaghoubi and Dahmardeh (2010), as cited in Arokodare (2020), proposed that an appropriate means of survival and prosperity for organizations is to focus on their strategic response as this would assist in achieving an absolute response to the changing external environment. In general terms, response agility enhances firms' ability to increase market share, satisfy erratic consumer taste, facilitating new product development speed, and minimize the operational cost attributable to environmental surprises. Kabue et al., (2019), within the context of manufacturing in Kenya, posited that strategic response capability explained positive and significant association with SMEs' performance in export business. Similarly, Masnan et al. (2018) revealed that strategic response capability in adaptive and sensing capabilities offers significant improvement for business operations and, consequently, improves Malaysia's SME performance. 
Within the context of local Oil marketing companies in Kenya, Muchiri et al. (2017) revealed that strategic response capability has a positive and significant association with firm performance, hence presenting the local oil marketing firms the opportunity to cope with stiff competition in Kenya's market environment. The findings in Semerciöz et al. (2015) suggested a significant relationship between strategic responses, management practices, and customer loyalty. The conceptual logic around the finding suggests that organizations who achieve customer loyalty status will enjoy repeated customer patronage, which consequently improves organization performance. Several empirical studies on strategic response capability that explained positive and significant contribution to firm performance regardless of research settings include Arokodare (2020) in Oil and gas industry, Imalingat (2015) in the Banking industry, Ketchen \& Palmer (2013) in the textile industry, Kimunguyi (2013) in the agrochemical industry, Collins (2014) in the manufacturing industry and Akinyele and Fasogbon (2010) in-service industry. All these studies lay credence for the relevance of strategic response capability for firm performance. This study posits that strategic response capability will significantly influence a firm's competitiveness on the strength of this discussion.

\subsubsection{Moderating Effect of Omoluabi Leadership}

The relevance of leadership to organizational performance either as a first-order condition or a secondorder condition has been documented in extant literature focusing on different context such as small business (Dunne et al., 2016; Lawal et al., 2014), health science library (Uzohue et al., 2016), and service firms (Anning-Dorson, 2018). Managing a successful organization, particularly in a challenging environment, is preconditioned for effective leadership (Hao \& Yazdanifard, 2015), positively influencing the organizational climate and structure. Such performance is premised on appropriate leadership philosophy. For example, Lawal et al. (2014) posited that SMEs in Nigeria who exhibit autocratic leadership had an insignificant relationship with organizational effectiveness. The ripple effect of the insignificant relationship becomes one of the many factors why SMEs report declining performance.

The study by Al Bourini et al. (2015) in Iraq, contrary to Lawal et al. (2014), found that leadership's performance effect was positive and statistically significant. Flanigan et al. (2017) established that leadership (transformational) explained significant variation in financial performance in the service industry. Besides, Obeidat and Tarhini (2016) corroborated the findings of Al Bourini et al. (2015) by revealing that leadership contributes significantly to job performance and, consequently, firm performance. Also, it was found that transactional leadership impacted knowledge sharing, whereas transformational leadership did not. Prasad and Junni (2016) share similarities with Obeidat and Tarhini (2016) in using transactional and transformational leadership; however, they differ in the outcome 
variables investigated. Prasad and Junni (2016) focused on organizational innovation, and the study established that both the transactional and transformational leadership affect organizational performance, leading to positive contributions to organizational innovation. Further analysis showed that in a fastchanging environment, transformational leadership's contribution is more compared with transactional leadership.

Considering the moderating effect of Omoluabi leadership on the interaction between response capability and firm's competitiveness is new, this study adopts a more general approach to discuss leadership and also provide a theoretical explanation for the moderating effect of Omoluabi leadership on the interaction between strategic response capability and firm competitiveness. Anning-Dorson (2018) posited that organizational leadership explained the interactions between firm-level capability (market innovation) and firm competitiveness more so that the interaction is statistically significant. Other studies shared similar outcomes, including Crossland and Hambrick (2007) and Anning-Dorson (2017). The implication of these studies' findings suggests that leadership permeates the entire organizational architecture (structure, process, climate, strategy, employee engagement) and largely determines a strategy's success.

The rarity of studies that established the link between strategic response capability, Omoluabi leadership, and firm competitiveness, made it necessary to fit a theoretical explanation to substantiate a possible interaction. According to the interaction perception driven by the contingence theory of fit-as-moderator, the influence a predictor variable (strategic response capability) has on a dependent variable (firm competitiveness) is conditional on the level of a third variable (Omoluabi leadership), termed here as the moderator. The interactionist perspective explains a significant intervening mechanism (Omoluabi leadership) between a criterion variable (strategic response capability) and the outcome variable (firm competitiveness). Specifically, the moderating variable accounts for a significant improvement in the relation between the predictor and the criterion variable. Hence, on the strength of this theory, and because of the relevance of leadership to organizational success, the study posits that the interactionterm of strategic response capability and Omoluabi leadership will have a positive and statistically significant moderating effect on the functional relationship between strategic response capability and firm competitiveness amongst paint manufacturers in Lagos State, Nigeria.

\section{METHODOLOGY}

This study adopted the quantitative approach to research with the use of a cross-sectional survey design. This research approach enables the use of quantifiable data and ensures data collection at a point in time. 


\subsection{The Study Context, Sampling and Data Collection}

The population of this study comprised of eighteen registered paint manufacturers in Lagos State. Using Conchran's (1963) formulate for calculating sample size from an infinite population, 384 was considered a representative sample. The analysis unit was top and middle management level employees in the selected companies who had significant years of work experience. The study used a structured questionnaire to collect data because it allows collecting relevant feedback based on the respondents' opinion about issues under investigation, and it enables quantitative analysis (Onamusi et al., 2019). The items in the questionnaire were adapted. The adapted questionnaire was a standardized scale that has been used by authors on the subject matter of this research in another research context. The response options provided in this study's questionnaire followed the 6 -point Likert type scale $(6=$ strongly agree, 1 = strongly disagree). The administration and retrieval of the questionnaire took eight weeks. After screening the collected questionnaires, 343 copies of the questionnaire were considered usable, representing an $89.3 \%$ response rate.

\subsection{Variables and Measures}

Given this study's objective, the following independent (strategic response capability), moderating (Omoluabi leadership), and dependent (firm competitiveness) variables were discussed in concomitant with their measurement in extant literature.

Independent, Moderation, and Dependent Variables

Strategic Response Capability (SRC)

SRC measures the extent to which the firm can respond (either proactively or reactively) to events in its business environment that can influence its overall organizational performance (Muchiri et al., 2017; Imalingat, 2015). Extant literature considered two-dimensions, which are internal response and external response capability, as a way to comprehensively define strategic response capability (Arokodare et al., 2019; Muchiri et al., 2017). By measurement, SRC includes but is not limited to; having a flexible business process, effective management resource planning, ability to collaborate with partners, ensuring quick changes to company policy, and possess competitor Knowledge.

Omoluabi Leadership

Conceived from a 'Yoruba' worldview (Yoruba is an ethnic group in Nigeria), the concept of Omoluabi describes the personality attribute of a person/leader that encapsulate the culture of hard work, transparency, accountability, respect for employees, possession of sound character, and wisdom in judgment; one equipped to handle problems both within and outside of the organization. More so, such individuals consistently use a socially approved expression in addressing employees, possess excellent 
knowledge of the business, and communicate effectively with the capacity to keep everyone's interest within the organization (Adebowale \& Onayemi, 2019; Akanbi \& Jekayinfa, 2016; Olanipekun, 2017).

\section{Firm Competitiveness}

In line with Akimova (2000), firm competitiveness measures the extent to which firms can produce and deliver marketing offerings that fulfill the following customers' aspirations: competitive pricing, product/service quality, time to achieve erratic customer desires, brand appeal, value propositions in selling and in product/service on offer, market coverage, market research, product performance and maximizing cost returns amongst others. Overall, this study follows a similar approach adopted by these prior studies to measure all the variables identified in this study and the use of a Likert-type scale structured questionnaire for assessment.

\subsection{Data Analysis}

The study employed hierarchical regression analysis to establish the moderating effect of Omoluabi leadership on the interaction between strategic response capability and firm competitiveness of eighteen manufacturers of paint in Lagos State, Nigeria. The model specification for this analysis is stated below $Y=f(X)$

$Y=$ Dependent variable: Firm competitiveness $(F C), X=$ Independent variables: Strategic Response Capability (SRC), Z = Moderating variables: Omoluabi Leadership (OL)

$Y=f(X)$

$Y=\beta 0+\beta_{1} X_{i}+\mu_{i}$

$F C=\beta 0+\beta_{1} S R C_{i}+\mu_{i}$

$Y=f(X Z)$

$Y=\beta 0+\beta_{1} X+\beta_{2} Z_{i}+\beta_{3} X_{Z_{i}}+\mu_{i}$

$F C=\beta O+\beta_{1} S R C_{i}+\beta_{2} \mathrm{OL}_{i}+\beta_{3} S_{R} C_{i}^{*} \mathrm{OL}_{i}+\mu_{i-1} \quad$-research model 2

For the purpose of this study, the above models were used.

\section{ANALYSIS AND RESULT}

\subsection{Validity and Reliability Test}

The principal component analysis was conducted to ascertain the overall adequacy and validity of the instrument. A Kaiser-Meyer-Olkin (KMO) statistic of 0.811 (strategic response capability, 0.755 (Omoluabi leadership), and 0.866 (firm competitiveness) which is more significant than 0.70 confirmed the suitability of the items for factor analysis (Onamusi, 2020). The factor loadings of these items were used to establish 
STRATEGIC RESPONSE CAPABILITY AND FIRM COMPETITIVENESS: HOW OMOLUABI LEADERSHIP MAKES A DIFFERENCE

the Average Variance Extracted (AVE). All the constructs have an AVE value above the threshold of 0.5 .

The construct, convergent validity, and reliability result are presented in Table 1 below.

TABLE 1: VALIDITY AND RELIABILITY TEST FOR MEASUREMENT ITEMS.

\begin{tabular}{|c|c|c|c|c|c|}
\hline Latent Variables & Items & Loadings & $\overline{C A}$ & $\overline{C R}$ & AVE \\
\hline Strategic & Speedy collective decision & 0.61 & 0.85 & 0.86 & 0.61 \\
\hline Response & Flexible business process & 0.78 & & & \\
\hline \multirow[t]{7}{*}{ Capability } & Management resource planning & 0.89 & & & \\
\hline & Sensitive to opportunity & 0.88 & & & \\
\hline & Quick changes to company policy & 0.73 & & & \\
\hline & Possess competitor Knowledge & 0.84 & & & \\
\hline & Marketing scanning for opportunities & 0.74 & & & \\
\hline & Explore new markets & 0.57 & & & \\
\hline & Adapt to changing business environment & 0.86 & & & \\
\hline Omoluabi & Respect for all employees & 0.89 & 0.862 & 0.918 & 0.78 \\
\hline \multirow[t]{7}{*}{ Leadership } & Sound character and wisdom in judgment & 0.66 & & & \\
\hline & Readiness to assist employees & 0.78 & & & \\
\hline & Truthful and reliable & 0.83 & & & \\
\hline & Able to handle problems adequately & 0.73 & & & \\
\hline & Able to discharge his duties responsibly & 0.85 & & & \\
\hline & Possess excellent knowledge of the business & 0.71 & & & \\
\hline & Consistent use of socially approved expression & & & & \\
\hline \multicolumn{6}{|c|}{ 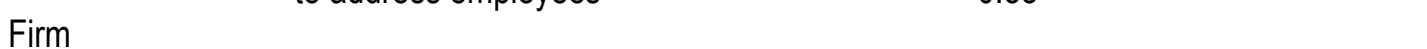 } \\
\hline \multirow[t]{5}{*}{ Competitiveness } & Motivated workforce & 0.71 & 0.787 & 0.83 & 0.71 \\
\hline & Unique product offering & 0.83 & & & \\
\hline & Acquire new market & 0.88 & & & \\
\hline & Brand reputation & 0.88 & & & \\
\hline & Reaching financial goals & 0.83 & & & \\
\hline
\end{tabular}

Source: Researcher's Results

TABLE 2: SUMMARY OF HIERARCHICAL REGRESSION ANALYSIS FOR THE MODERATING EFFECT OF OMOLUABI LEADERSHIP ON THE INTERACTION BETWEEN STRATEGIC RESPONSE CAPABILITY AND FIRM COMPETITIVENESS

\begin{tabular}{lccccccccc}
\hline Model & Beta & $\mathrm{t}$ & Sig. & $\mathrm{R}$ & $\mathrm{R}^{2}$ & $\begin{array}{c}\text { Adj. } \\
\mathrm{R}^{2}\end{array}$ & $\Delta \mathrm{R}^{2}$ & $\Delta \mathrm{F}$ & $\begin{array}{c}\text { Sig. } \mathrm{F} \\
\text { Change }\end{array}$ \\
\hline $\begin{array}{l}\text { (Constant) } \\
\text { Strategic }\end{array}$ & 1.874 & 10.073 & .000 & $.681^{\mathrm{a}}$ & .463 & .462 & .463 & 294.165 & .000 \\
$\begin{array}{l}\text { response } \\
\text { capability }\end{array}$ & .654 & 17.151 & .000 & & & & & & \\
$\begin{array}{l}\mathrm{F} \text { \& Anova Sig: } 294.165 \\
\text {.00 }\end{array}$ & $11,341), \mathrm{p}=$ & & & & & & & \\
(Constant) $^{2}$ & 1.392 & 5.251 & .000 & $.688^{\mathrm{b}}$ & .473 & .470 & .010 & 6.436 & \\
\hline
\end{tabular}




\begin{tabular}{|c|c|c|}
\hline $\begin{array}{l}\text { Strategic } \\
\text { response } \\
\text { capability }\end{array}$ & .659 & 17.391 \\
\hline $\begin{array}{l}\text { Omoluabi } \\
\text { leadership }\end{array}$ & .094 & 2.537 \\
\hline $\begin{array}{l}F \text { \& Anova Sig: } \\
p=.000\end{array}$ & 152.645 & $(2,340)$ \\
\hline (Constant) $^{3}$ & -4.37 & -3.838 \\
\hline $\begin{array}{l}\text { Strategic } \\
\text { response } \\
\text { capability }\end{array}$ & 1.873 & 7.909 \\
\hline $\begin{array}{l}\text { Omoluabi } \\
\text { leadership }\end{array}$ & .692 & 5.734 \\
\hline SRC*OML & -.026 & -5.189 \\
\hline
\end{tabular}

a. Predictors: (Constant), Strategic response capability (SRC)

b. Predictors: (Constant), Strategic response capability, Omoluabi leadership (OML)

c. Predictors: (Constant), Strategic response capability, Omoluabi leadership, SRC ${ }^{*} \mathrm{OML}$

d. Dependent Variable: Firm competitiveness

Source: Researcher's Results

In the first step (Model One), the effect of strategic response capability on firm competitiveness was examined. In the Second step (Model 2), the effect of strategic response capability and Omoluabi leadership on firm competitiveness was examined. In the third step (Model 2), the moderating effect of Omoluabi leadership on the interaction between Strategic response capability and Firm competitiveness was examined and discussed accordingly.

In the first model, it was discovered that strategic response capability accounted for $46.3 \%$ of the variance recorded in firm competitiveness ( $R 2=0.46 .3, F(1,341) 294.165, p=.000)$. In the second model, both strategic response capability and Omoluabi leadership explained $62.7 \%$ variation in firm competitiveness (Adj. $R 2=0.470, F(2,340) 152.645, p=.000$ ). In the third model, when the interaction term of strategic response capability ${ }^{*}$ Omoluabi leadership was added to the regression model, there was a significant additional increase in firm competitiveness by $3.9 \%(\Delta R 2=0.039, p=0.000)$ because $R 2$ increased from 0.473 to 0.512 . This result shows that Omoluabi leadership has a significant moderating effect on the interaction between strategic response capability and firm competitiveness. 


\section{DISCUSSION, CONCLUSION, LIMITATIONS, AND SUGGESTION FOR FURTHER STUDIES}

The study investigates the influence of strategic response capability on firm competitiveness and the moderating effect of Omoluabi leadership on the interaction between strategic response capability and firm performance. The findings align with the hypotheses formulated in this study hence providing important implications for theory and practice. The first hypothesis proposed that strategic response capability would positively affect firm competitiveness. This study shows that strategic response capability has a significant effect on firm competitiveness, and this aligns with past empirical studies (Arokodare, 2020; Collins, 2014; Imalingat, 2015; Kabue et al., 2019; Ketchen \& Palmer, 2013; Kimunguyi, 2013; Muchiri et al., 2017). Hence, upheld the narrative that possessing strategic response capability is a critical precondition for firm competitiveness.

The second hypothesis upholds the findings of several leadership studies to confirm the relevance of leadership (either as a first-order or a second-order condition) for organization performance (Al Bourini et al., 2015; Anning-Dorson, 2017; 2018; Dunne et al., 2016; Flanigan et al., 2017; Hao \& Yazdanifard, 2015; Obeidat \& Tarhini, 2016; Prasad \& Junni, 2016; Uzohue et al., 2016). Considering that Omoluabi leadership had a positive and significant moderating effect on the interaction between strategic response and firm competitiveness, the finding substantiates the Yoruba worldview's assertions that leaders who exhibit the Omoluabi values are highly like to enhance the operational efficiency of the society and, by extension the organization they lead. Benjamin (2020) and Olanipekun (2017) stressed that the individual who possesses these Omoluabi attributes has a unique capability, and such a person will be able to influence positive outcomes within the community. Hence, a leader who exhibits these Omoluabi personality traits is highly likely to significantly improve the firm's operational efficiency, motivate the employees, and consequently enhance firm performance.

Also, by this study's result, the interactionist perspective of fit-as-mediator is strengthened because the effect-relationship between two variables is explained by introducing a third variable (in this case, strategic response capability) then the interactionist perspective of fit-as-mediator holds. This study strongly affirms this position with its result.

The contribution of this study to knowledge is in many ways. First, the study conceptualized leadership attributes from the Yoruba worldview and infuse them in a strategic management study. Also, the study developed the questionnaire items that addressed Omoluabi leadership. Thus, creating relevance for the Yoruba concept in strategic management pushes forward the frontier of knowledge in both fields. Theoretically, this study's finding provides additional support for the dynamic capability theory's 
assumptions and the interaction perspective. The study concluded that strategic response capability benefits firm competitiveness, and such competitiveness is enhanced through leadership that exhibits the Omoluabi attributes. Hence, this study recommends that firms strengthen their strategic response capability and encourage leadership to imbibe the philosophy of Omoluabi leadership; this is because such a leadership attribute can aid organizational effectiveness and efficiency.

This study has limitations that must be acknowledged to provide opportunities for future studies. First of all, the study focused only on the registered paint manufacturers in Lagos, Nigeria. As with any single industry studies, this study's findings are more appropriate for managers in this line of business. The adoption of a cross-sectional survey design equally suggests that the study cannot explain the changes in the dependent variable attributable to the independent and moderating variable over a long period. Future studies may consider a multiple industry analysis to see if they can generalize this study's findings. Also, studies that want to explain causality over time about this study's interactions may consider a longitudinal study. Despite these limitations, this study provides important conceptual, empirical, theoretical, and practical implications for managers regarding the link between strategic response capability, Omoluabi leadership, and firm competitiveness.

\section{REFERENCES}

Adebowale, B. A., and F.Onayemi . (2019). Aristotle's Human Virtue and Yorùbá Worldview of Omoluabi: An Ethical-cultural Interpretation. African Philosophical Inquiry. 6: 27-44.

Afsar, B., Badir, Y. F., Saeed, B. B., \& Hafeez, S. (2017). Transformational and transactional leadership and employee's entrepreneurial behavior in knowledge-intensive industries. The International Journal of Human Resource Management, 28(2): 307-332.

Akanbi, G. O. \& Jekayinfa A. A. (2016). Reviving the African culture of 'Omoluabi' in the Yoruba race as a means of adding value to education in Nigeria. International Journal of Modern Education Research, 3(3): 13-19.

Akimova, I. (2000). Development of market orientation and competitiveness of Ukranian firms. European Journal of Marketing, 34(9/10): 1128-1248.

Akinboye, G. (2015). "Reviving the values of Omoluabi and the virtues of Aristotle: Accelerating the African/Yoruba communitarian efflorescence. Nigerian Community Development Journal, 3(1): 21-39.

Akinyele, S. T., \& Fasogbon, O. I. (2010). Impact of strategic planning on organizational performance and survival. Research Journal of Business Management, 4(1): 73-82.

Al Bourini, F., Abu-Rumman, H. A., \& Alhadid, Y. A. (2015). The impact of leadership style as a moderator variable on the relationship between leadership practices and organizational performance analytical study on Jordanian commercial banks. Journal of Advanced Social Research, 5(2): 1-10.

Anning-Dorson, T., Odoom, R.K., Acheampong, G., \& Tweneboah-Koduah, E. (2017), Innovation and organizational development: The role of organizational leadership. African Journal of Economic and Management Studies, 8(3): 338-351. 
Anning-Dorson, T. (2018), Innovation and firm competitiveness creation: The role of organisational leadership in service firms from emerging markets. International Marketing Review, 35(4): 580-600.

Arokodare, M. A. (2020). Strategic agility: Achieving superior organizational performance through strategic foresight. Global Journal of Management and Business Research, 20(2): 7-16.

Arokodare, M. A., Asikhia, O. U., \& Makinde, G. O. (2019). Strategic agility and firm performance: The moderating role of organisational culture. Business Management Dynamics, 9(3): 01-12.

Asikhia, O. U., \& Makinde, G. O., \& Onamusi, A. B. (2020). Marketing capability and firm performance: Mediating role of new product development and management innovation. The International Journal of Business \& Management, 8(2): 69-77.

Bartocci, L. (2019). Dynamic capabilities for sustainability: Revealing the systemic key factors. Systemic Practice and Action Research, 32(1): 93-112.

Benjamin, T. O. (2020) Situational ambivalence of the meaning of life in Yorùbá thought. South African Journal of Philosophy, 39(2): 219-227.

Breznik, L., \& Lahovnik, M. (2016). Dynamic capabilities and competitive advantage: Findings from case studies. Journal of Contemporary Management Issues, 21(Special issue): 167-185.

Collins, R. (2014). Strategic responses by manufacturing firms in the Netherlands, (PDF), Retrieved 26 April, 2016.

Crossland, C., \& Hambrick, D. C. (2007). How national systems differ in their constraints on corporate executives: A study of CEO effects in three countries. Strategic Management Journal, 28(8): 767789.

Deichmann, D., \& Stam, D. (2015). Leveraging transformational and transactional leadership to cultivate the generation of organization-focused ideas. The Leadership Quarterly, 26(2): 204-219.

Dunne, T. C., Aaron, J. R., McDowell, W. C., Urban, D. J., \& Geho, P. R. (2016). The impact of leadership on small business innovativeness. Journal of Business Research, 69(11): 4876-4881.

Flanigan, R., Bishop, J., Brachle, B., \& Winn, B. (2017). Leadership and small firm financial performance: The moderating effects of demographic characteristics. Creighton Journal of Interdisciplinary Leadership, 3(1): $2-19$.

Gerald, E., Obianuju, A., \& Chukwunonso, N. (2020). Strategic agility and performance of small and medium enterprises in the phase of Covid-19 pandemic. International Journal of Financial, Accounting, and Management, 2(1): 41-50.

Gill, C., Gardner, W., Claeys, J., \& Vangronsvelt, K. (2018). Using theory on authentic leadership to build a strong human resource management system. Human Resource Management Review, 28(3): 304318.

Hao, M. J., \& Yazdanifard, R. (2015). How effective leadership can facilitate change in organizations through improvement and innovation. Global journal of management and business research, 15(9): $1-5$.

Ibarra, H. (2015). The authenticity paradox. Harvard Business Review, 93(1/2): 53-59.

Imalingat, S. (2015). Strategic responses of mobile money transfer service in Barclays bank in Kampala, Uganda, Published Master Thesis, Bugema University.

Kabue, S. T., Oloko, M. A., \& Muturi, W. (2019). Relationship between strategic response capability and export performance of manufacturing firms in Kenya. The Strategic Journal of Business \& Change Management, 6(4): 980 - 991. 
Ketchen, D., \& Palmer, T. (2013). Strategic responses to poor organizational performance: A test of competing perspectives, Psychology Management, 4,185

Kimunguyi, E. S. (2013). Response strategies adopted by agrochemical companies to the challenges of agrochemical distribution in Kenya, published MBA Project, University of Nairobi

Laaksonen, O., \& Peltoniemi, M. (2016). The essence of dynamic capabilities and their measurement. International Journal of Management Reviews, 20(2): 184-205.

Lawal, A. A., Ajonbadi, H. A., \& Otokiti, B. O. (2014). Leadership and organisational performance in the nigeria small and medium enterprises. American Journal of Business, Economics and Management, 2(5): $121-127$.

Lin, D., Lee, C. K., \& Yang, Y. (2018). Strategic response to Industry 4.0: an empirical investigation on the Chinese automotive industry. Industrial Management \& Data Systems, 118(3): 589-605.

Masnan, F., Saad, N. M., \& Ramlee, A. A. (2018). Assessing the implications of dynamic capability and international opportunity recognition on export performance of manufacturing SMEs in Malaysia. International Journal of Academic Research in Business and Social Sciences, 8(8): 361-374.

Muchiri, L., Ombui, K., \& Iravo, M. A. (2017). Impact of strategic responses on the performance of oil marketing companies in Kenya. International Journal of Scientific and Research Publications, 7(10).

Ngo, L. V., Bucic, T., Sinha, A., \& Lu, V. N. (2019). Effective sense-and-respond strategies: Mediating roles of exploratory and exploitative innovation. Journal of Business Research, 94(2): 154-161.

Nwonu, C. O., Agbaeze, E. K., \& Obi-Anike, H. O. (2017). Effect of organisational structure on performance of selected manufacturing companies in Enugu state Nigeria. The International Journal of Business \& Management, 5(5): 190-206.

Olanipekun, O. V. (2017). Omoluabi: Re-thinking the Concept of Virtue in Yoruba Culture and Moral System: Africology, 10(9): 217-231.

Ogunkoya, A., Hassan, B. A., \& Shobayo, P. A. (2014). Dynamic capabilities and competitive advantage: An analysis of the Nigerian banking sector. Journal of Accounting and Management, 4(2): 29-36.

Oke, O. P. (2016). Plea bargaining and the religious cum socio-cultural concept of Yoruba omọlúàbí in the Nigerian political landscape. Ilorin Journal of Religious Studies, 6(1): 31-46.

Oliveira, J. S., Yazdani, N., Cadogan, J. W., Hodgkinson, I. R., Tsougkou, E., Jean, R., Boso, N. (2018). The empirical link between export entry-mode diversity and export performance: A contingency and institutional-based examination. Journal of Business Research, 88(6): 505-512.

Onamusi, A.B. (2020). Entry mode strategy, customer engagement and firm performance. Journal of Business and Social Review in Emerging Economies, 6(1): 99-112

Onamusi, A. B., Asikhia, O. U., \& Makinde, O. G. (2019). Environmental munificence and service firm performance: The moderating role of management innovation capability. Business Management Dynamics, 9(6): 13-25.

Prasad, B. and Junni, P. (2016), "CEO transformational and transactional leadership and organizational innovation: The moderating role of environmental dynamism", Management Decision, 54(7): 15421568.

Semerciöz, F., Pehlivan, Ç., Sözüer, A., \& Mert, A. (2015). Crisis management practices and strategic responses through customer loyalty and price strategy in hard times: Evidence from fine-dining restaurants. Procedia-Social and Behavioral Sciences, 207, 149-156.

Titus, V. K., \& Anderson, B. S. (2018). Firm structure and environment as contingencies to the corporate venture capital-parent firm value relationship. Entrepreneurship Theory and Practice, 42(3): 498-522. 
Uzohue, C. E., Yaya, J., \& Akintayo, O. A. (2016). A review of leadership theories, principles, styles and their relevance to management of health science libraries in Nigeria. Journal of Educational Leadership and Policy, 1(1): 17-26.

Wang, C. L., Senaratne, C., \& Rafiq, M. (2015). Success traps, dynamic capabilities and firm performance. British Journal of Management, 26(1): 26-44. 